\title{
Quercetrin from Toona sinensis leaves induces cell cycle arrest and apoptosis via enhancement of oxidative stress in human colorectal cancer SW620 cells
}

\author{
YALI ZHANG $^{1}$, YUCHENG GUO ${ }^{1}$, MIMI WANG $^{1}$, HUANHUAN DONG ${ }^{1}$, \\ JINGFANG ZHANG ${ }^{2}$ and LIYU ZHANG ${ }^{3}$
}

\begin{abstract}
${ }^{1}$ Key Laboratory of Biomedical Information Engineering of Ministry of Education, School of Life Science and Technology, Xi'an Jiaotong University, Xi'an, Shaanxi 710049; ${ }^{2}$ College of Forestry, Northwest A\&F University, Yangling, Shaanxi 712100;

${ }^{3}$ Shaanxi Institute of Pediatric Diseases, Xi'an Children's Hospital, Xi'an, Shaanxi 710049, P.R. China
\end{abstract}

Received April 1, 2017; Accepted September 15, 2017

DOI: $10.3892 /$ or.2017.6042

\begin{abstract}
Finding effective strategies against colorectal cancer (CRC) is still an emergent health problem. In the present study, we investigated the anticancer activity of quercetrin from Toona sinensis leaves (QTL) and explored the underlying mechanism in human CRC cell line SW620. The cells were treated with various concentrations of QTL and the cytotoxic effects of QTL were determined using the MTT assay. Apoptosis and cell cycle status were detected by flow cytometry. Reactive oxygen species (ROS) levels and mitochondrial membrane potential $\left(\Delta \Psi_{\mathrm{m}}\right)$ were assessed using DCF-DA and JC-1 fluorescence spectrophotometry, respectively. Western blot analysis was used to quantify the expression of apoptosis-related proteins. RT-PCR was applied to determine the mRNA levels of glutathione peroxidase (GPx) and catalase (CAT). QTL exhibited growth inhibitory effects and caused cell cycle arrest in the G2/M phase, which was accompanied by increased expression of $\mathrm{p} 53$ and $\mathrm{p} 21$ proteins. QTL promoted apoptosis which was consistent with the upregulated expression
\end{abstract}

Correspondence to: Dr Jingfang Zhang, College of Forestry, Northwest A\&F University, Yangling, Shaanxi 712100, P.R. China E-mail: zjf19890117@163.com

Abbreviations: CRC, colorectal cancer; QTL, quercetrin from Toona sinensis leaves; ROS, reactive oxygen species; $\Delta \Psi \mathrm{m}$, mitochondrial membrane potential; MDA, malondialdehyde; SOD, superoxide dismutase; GPx, glutathione peroxidase; CAT, catalase; NAC, $N$-acetyl cysteine; DMEM, Dulbecco's modified Eagle's medium; DMSO, dimethyl sulfoxide; RT-PCR, reverse transcriptase-polymerase chain reaction; MTT 3-(4,5-dimethylthiazol-2-yl)-2,5-diphenyltetrazolium bromide; DCFH-DA, 2',7'-dichlorofluorescin diacetate; FBS, fetal bovine serum; JC-1, 5,5',6,6/-tetra'hloro-1,1/,3,3/-tetraethylbenzimidazolyl carbocyanine iodide; GSH, glutathione

Key words: quercetrin from Toona sinensis leaves, cell cycle arrest, apoptosis, oxidative stress, colorectal cancer of Bax, cytochrome $c$, caspase-9, Apaf-1 and caspase-3. In addition, QTL induced the loss of mitochondrial membrane potential and triggered ROS generation, as revealed by the downregulated mRNA expression and enzymatic activity of GPx and CAT. Furthermore, both $N$-acetyl cysteine (NAC) and GSH attenuated the QTL-induced growth inhibition observed in SW620 cells along with the increase of ROS levels. These findings revealed that QTL inhibited the growth of CRC cells and facilitated apoptosis by enhancing oxidative stress. QTL may therefore have potential for use in CRC chemotherapy.

\section{Introduction}

Colorectal cancer (CRC) is the third most common cancer and the fourth leading cause of cancer mortality (1). Therefore, finding strategies to combat $\mathrm{CRC}$ is still an emergent health problem. Phytochemicals can inhibit CRC by disrupting multiple mechanisms that are central to cancer progression $(2,3)$. Flavonoids are one of the most numerous and widely distributed family of phytochemicals in different types of vegetables and fruits. Compared with conventional anticancer drugs, plant-derived flavonoids have an extra margin of safety since they show only marginal toxicity even at relatively high concentrations $(2,3)$.

Leaves of Toona sinensis (T. sinensis) M.Roem., a popular vegetable in China, were reported to have various biologically activated effects including antioxidative (4-6), anticancer (7-9), anti-inflammatory (10-12) and anti-hyperglycemic $(13,14)$. Crude water extracts of $T$. sinensis leaves have been shown to inhibit cell proliferation and induce apoptosis of a number of human cancers, including lung adenocarcinoma (A549) cells (15), human SKOV3 ovarian cancer cell lines (16), HL-60 leukemia cells $(8,17,18)$, H661 lung (19) and cervical carcinoma HeLa cells (20), HepG liver cancer (21) and MCF-7 breast cancer cell (21), and prostate cancer cells (22). Antiproliferative effects on Caco-2 human colon cancer cells have also been reported (21). Although $T$. sinensis leaves have been used medicinally for a long time, its effects are still not fully understood.

A previous study demonstrated that $T$. sinensis leaf extracts are rich in active ingredients such as flavonoids, volatile oils 
and alkaloids (17). The major identified flavonoids in QTL are quercetrin, kaempferol-3-O- $\alpha$-L-rhamopyranoside, astragalin, quercetin, kaempferol, methyl and ethyl gallate, and 1,2,3,4,6-penta- $O$-galloyl- $\beta$-D-glucopyranose $(4,17)$. The present study was undertaken to evaluate the growth-inhibitory and apoptosis-inducing effects of QTL and the probable molecular mechanisms in the SW620 human CRC cell line.

\section{Materials and methods}

Materials. Dulbecco's modified Eagle's medium (DMEM), dimethyl sulfoxide (DMSO), 3-(4,5-dimethylthiazol-2-yl)2,5diphenyltetrazolium bromide (MTT) 2',7'-dichlorofluorescin diacetate (DCFH-DA), $N$-acetyl cysteine (NAC) and glutathione (GSH) were obtained from Sigma (St. Louis, MO, USA), and fetal bovine serum (FBS) was purchased from Gibco (Paisley, UK). 5,5',6,6'-Tetrachloro-1,1',3,3'-tetraethylbenzimidazolyl carbocyanine iodide (JC-1) were purchased from Beyotime Institute of Biotechnology (Shanghai, China). The commercially available assay kits used detect the content of malondialdehyde (MDA), and the activity of SOD, GPX and CAT were purchased from the Institute of Jiancheng Biological Engineering (Nanjing, China). The primers for superoxide dismutase (SOD), glutathione peroxidase (GPx) and catalase (CAT) were designed and synthesized by Takara Biotechnology Co., Ltd. (Dalian, China). Reagents, such as enzymes, co-factors and nucleotides for internal standard construction and reverse transcriptase-polymerase chain reaction (RT-PCR) were obtained from Takara Biotechnology Co., Ltd. Rabbit anti-active p53, p21, Bax, cytochrome $c$, caspase-9, Apaf-1 and caspase-3 polyclonal antibodies were purchased from Cell Signaling Technologies (Beverly, MA, USA) and $\beta$-actin antibodies were purchased from Santa Cruz Biotechnology (Santa Cruz, CA, USA). Other chemicals were analytical grade.

Preparation of QTL. Leaves of $T$. sinensis were collected in Shaanxi Province (China), in August 2015 and authenticated by experts in the College of Forestry, Northwest A\&F University (Shaanxi, China). T. sinensis leaves (50 g) were cut into pieces of $\sim 2 \mathrm{~cm}$ in width and were dried. The leaves were then soaked in a $70 \%$ ethanol solvent $(1: 10, \mathrm{w} / \mathrm{v})$ for $2.5 \mathrm{~h}$ and were sonicated in an ultrasonic bath at $200 \mathrm{kHz}$ at $55^{\circ} \mathrm{C}$ for $45 \mathrm{~min}$. The samples were then filtered through a $0.45 \mu \mathrm{m}$ microporous membrane (Shanghai Wanzi Shiye Co., Ltd., Shanghai, China). The filtrate was collected, and the solid was extracted two additional times using the same volume of fresh solvent. The combined solutions were concentrated and dried using a rotary evaporator. The dried crude extract was added to distilled water and defatted with petroleum ether and ethyl acetate. The ethyl acetate fractions of $T$. sinensis leaves, eluted with EtOAc MeOH (8:1), were further separated and purified by capillary electrophoresis using silica gel column chromatography to yield quercetrin. QTL was concentrated and dried using a rotary evaporator.

QTL was dissolved in DMSO immediately before use, and the final concentration of DMSO did not exceed $0.1 \%(\mathrm{v} / \mathrm{v})$ in any of the experiments. Concentrations of QTL ranged from $12.5-400 \mu \mathrm{g} / \mathrm{ml}$. DMSO at $0.1 \%$ was used as a control. All determinations were performed in triplicate.
Cell culture. SW620 cells were maintained in DMEM supplemented with $10 \%$ heat-inactivated FBS, $100 \mathrm{U} / \mathrm{ml}$ penicillin and $100 \mu \mathrm{g} / \mathrm{ml}$ streptomycin (Thermo Fisher Scientific, Franklin Lakes, NJ, USA) in a humidified $5 \% \mathrm{CO}_{2}$ incubator at $37^{\circ} \mathrm{C}$. The medium was changed every $48 \mathrm{~h}$. SW620 cells were cultured in 24- or 96-well plates.

Cell viability. The cell survival rate was quantified using a colorimetric MTT assay. Briefly, aliquots $(20 \mu \mathrm{l})$ of the $2.5 \mathrm{mg} / \mathrm{ml}$ MTT stock solution were pipetted into each well, and the plate was incubated at $37^{\circ} \mathrm{C}$ in a humidified $5 \% \mathrm{CO}_{2}$ incubator. After $4 \mathrm{~h}$, the medium was removed, and DMSO (200 $\mu \mathrm{l}$ ) was added to each well to dissolve the formazan. The optical density of each well was assessed 10 min later at $570 \mathrm{~nm}$ by a spectrophotometer (Tecan Infinite M200 PRO; Tecan, Männedorf, Switzerland).

Flow cytometric analysis of the cell cycle. Cell suspensions $\left(0.5-1 \times 10^{5} / \mathrm{ml}\right)$ were prepared by trypsinization and washed twice with phosphate-buffered saline (PBS). The cells were then fixed with $70 \%$ ethanol at $4^{\circ} \mathrm{C}$ and resuspended in PBS containing $0.25 \mathrm{mg} / \mathrm{ml}$ of RNase A (Thermo Fisher Scientific). The suspension was incubated for $30 \mathrm{~min}$ at $37^{\circ} \mathrm{C}$, and then the cells were labeled with propidium iodide (PI) $(50 \mu \mathrm{g} / \mathrm{ml})$. The total DNA content was quantified by fluorescence using a Becton-Dickinson (BD Biosciences, San Jose, CA, USA) FACS flow cytometer.

Flow cytometric analysis for apoptosis. Prepared SW620 cells $\left(1 \times 10^{6} / \mathrm{ml}\right)$ were washed twice with cold PBS, and then re-suspended gently in $500 \mu 1$ binding buffer. Thereafter, the cells were stained in $5 \mu \mathrm{l}$ Annexin V-FITC and well shaken. Finally, $5 \mu \mathrm{l}$ PI was added to these cells and incubation for $20 \mathrm{~min}$ in a dark place followed. Subsequently, the cells were analyzed by FACS flow cytometer, Becton-Dickinson (BD Biosciences).

Western blotting. Cell lysates (30 $\mu \mathrm{g}$ of total protein) were analyzed on 8-12\% SDS-PAGE under a gradient concentration. The proteins were transferred to an immunoblot polyvinylidene fluoride (PVDF) membrane (Millipore, Billerica, MA, USA), which was blocked with 5\% skim milk in TBS containing $0.1 \%$ Tween-20 (TBS-T) for $1 \mathrm{~h}$. Subsequently, the primary monoclonal antibodies were added to the TBS-T at a 1:1,000 dilution and were incubated for $1 \mathrm{~h}$. Primary antibody bindings were detected using a secondary antibody conjugated to horseradish peroxidase and enhanced using an enhanced chemiluminescence (ECL) assay kit (Amersham Pharmacia Biosciences, Buckinghamshire, UK) according to the manufacturer's instructions. Chemiluminescence was imaged on a FujiFilm LAS-3000 system (FujiFilm, Tokyo, Japan). The basal levels of proteins were normalized to the level of $\beta$-actin protein.

Assessment of the mitochondrial membrane potential $\left(\Delta \Psi_{m}\right)$. The mitochondrial membrane potential $\left(\Delta \Psi_{\mathrm{m}}\right)$ was analyzed by fluorescence spectrophotometry using a JC-1 dye. In brief, SW620 cells were stained with $5 \mathrm{mM} \mathrm{JC}-1$ at $37^{\circ} \mathrm{C}$ for $20 \mathrm{~min}$ in $5 \% \mathrm{CO}_{2}$. The cells were pelleted by centrifugation $\left(5,000 \mathrm{rpm}\right.$ for $5 \mathrm{~min}$ at $\left.4^{\circ} \mathrm{C}\right)$, and then resuspended in PBS. The JC-1 fluorescence of the cell suspensions and PBS controls were assessed in triplicate in Costar 96-well plates using a 
microplate reader [Ex/Em (green)/(red): 485/538/590 nm] (Tecan Infinite M200 PRO). FL2/FL1 ratios were then calculated. Each well was scanned by measuring the intensity of each 25 -square grid (of a $1 \mathrm{~mm}^{2}$ area), which was arranged in a $5 \times 5$ rectangular array (bottom scanning). A higher red-to-green ratio indicated a more polarized or more negative and hyperpolarized mitochondrial inner membrane.

Assessment of intracellular ROS level. Cellular ROS level was assessed using the dichlorofluorescein assay. Cells were collected and incubated with $100 \mu \mathrm{M}$ DCF-DA (dissolved in DMSO) for $30 \mathrm{~min}$ at $37^{\circ} \mathrm{C}$. Then, the cells were washed three times with PBS ( $\mathrm{pH}$ 7.4) and the relative levels of fluorescence were quantified on a spectrophotofluorimeter (Tecan Infinite M200 PRO). The measured fluorescence values were expressed as a percentage of the fluorescence in control cells.

Assays on the content of MDA and the activity of GPX, SOD and CAT. The content of MDA and the activity of SOD, GPx and CAT were determined by commercially available assay kits following the manufacturer's protocols. The level of lipid peroxidation was indicated by the amount of MDA in the cells as assayed using the thiobarbituric acid reactions (TBARS). The absorbance was read at $548 \mathrm{~nm}$. The CAT activity was determined by measuring the decrease in absorbance at $405 \mathrm{~nm}$ due to the degradation of $\mathrm{H}_{2} \mathrm{O}_{2}$. The SOD activity was spectrophotometrically determined at $550 \mathrm{~nm}$, indicating the inhibition of the oxidation of oxymine by the xanthine/xanthine oxidase system. The GPx activity was assayed by quantifying the oxidation rate of glutathione to oxidized glutathione by $\mathrm{H}_{2} \mathrm{O}_{2}$ at $412 \mathrm{~nm}$. The protein concentration was assessed using the BCA protein assay kit (Pierce, Rockford, IL, USA) with BSA as a standard.

Quantitative RT-PCR analysis. Cells were washed in ice-cold PBS, and RNA was extracted using TRIzol reagent (BioTeke Corporation, Beijing, China) as described by the manufacturer. cDNA was synthesized from mRNA using a PrimeScript ${ }^{\mathrm{TM}}$ RT reagent kit, followed by RT-PCR using a SYBR Premix Ex Taq ${ }^{\mathrm{TM}}$ reagent kit (both from Takara, Dalian, China) and the ABI PRISM 7500 sequence detection system (Applied Biosystems, Foster City, CA, USA). The reactions were performed with the following cycling conditions: $95^{\circ} \mathrm{C}$ for $30 \mathrm{sec}$, followed by 40 cycles of $95^{\circ} \mathrm{C}$ for $5 \mathrm{sec}$ and $56^{\circ} \mathrm{C}$ for $30 \mathrm{sec} . \beta$-actin was used as a housekeeping gene for normalization. All experiments were repeated at least three times. The relative change in gene expression was analyzed using the $2^{-\Delta \Delta \mathrm{Ct}}$ method. The sequences for the RT-PCR primers were as follows: primers for SOD were: 5'-CTT TGT TGC CGT GCG ATG-3' (forward) and 5'-CTA ACC CCG TGA ATG GAC AGA-3' (reverse); GPx, 5'-CCT CTA AAC CTA CGA GGG AGG AA-3' (forward) and 5'-GGG AAA CTC GCC TTG GTC T-3' (reverse); primers for CAT, 5'-TCC AAG GCA AAG GTA TTT GAG CA-3' (forward) and 5'-CAA CGA GAT CCC AGT TAC CAT CTT C-3' (reverse); primers for $\beta$-actin, 5'-CAT CCG TAA AGA CCT CTA TGC CAA C-3' (forward) and 5'-ATG GAG CCA CCG ATC CAC A-3' (reverse).

Statistical analysis. All data are expressed as the means \pm SD of at least three independent determinations for each experiment.
Statistical analyses were performed using SPSS version 13.0 (SPSS, Inc., Chicago, IL, USA). A one-way ANOVA with Duncan's multiple range test was used to examine differences between groups. $\mathrm{P}<0.05$ was considered significant.

\section{Results}

Cell growth inhibition and morphological changes. The growth inhibitory potential of QTL $(12.5-400 \mu \mathrm{g} / \mathrm{ml})$ in SW620 human CRC cells at different time-points after addition (24, 48 and $96 \mathrm{~h})$ is shown in Fig. 1A. Treatment with QTL exhibited significant growth inhibition in a dose- and time-dependent manner. The results clearly revealed that when SW620 cells were treated with QTL for a prolonged period $(96 \mathrm{~h})$, the $\mathrm{IC}_{50}$ values were the lowest $(75.11 \mu \mathrm{g} / \mathrm{ml})$. By contrast, when the cells were treated with QTL for a short time (24 and $48 \mathrm{~h}$ ), the $\mathrm{IC}_{50}$ values were higher (198.21 and $112.55 \mu \mathrm{g} / \mathrm{ml}$, respectively).

When the cells were treated with different concentrations of QTL for $48 \mathrm{~h}$, morphological changes of SW620 cells were marked (Fig. 1B). The cells treated with $50 \mu \mathrm{g} / \mathrm{ml}$ of QTL exhibited swelling, shrinkage accompanied by rounding of cells, and membrane blebbing. Cells incubated with $100 \mu \mathrm{g} / \mathrm{ml}$ of QTL shrunk and exhibited disrupted intercellular contacts. In the group treated with $200 \mu \mathrm{g} / \mathrm{ml}$ of QTL, the cells were binucleated and the majority of the cells were detached from the wells, indicating cell death.

Analysis of cell cycle and apoptosis status. SW620 cells were exposed to QTL (50, 100 and $200 \mu \mathrm{g} / \mathrm{ml}$ ) for $48 \mathrm{~h}$, then washed, harvested and analyzed by flow cytometry. A dose-dependent increase of cells in the G2/M phase indicated the induction of a G2/M phase arrest (Fig. 2A and B). Western blot analysis revealed that QTL increased the p53 and p21 protein expression levels compared with the control groups (Fig. 2C and D), which was in accordance with the results of the cell cycle analysis.

As shown in Fig. 3A, untreated cells did not exhibit any significant signs of apoptosis, whereas the cells became apoptotic after treatment with 50, 100 and $200 \mu \mathrm{g} / \mathrm{ml}$ QTL for $48 \mathrm{~h}$, with apoptotic populations encompassing $\sim 10.2,11.5$ and $24.0 \%$ of the total, respectively (Fig. 3A). The protein levels of apoptosis markers Bax, cytochrome $c$ caspase-9, Apaf-1 and caspase-3 exhibited a significant $(\mathrm{P}<0.01$ in all cases) increase after treatment with $200 \mu \mathrm{g} / \mathrm{ml}$ of QT compared with their respective expression levels in the control groups (Fig. 3B-G). Our results therefore revealed that the QTL-induced apoptotic response may be mediated by a mitochondrial-dependent apoptotic pathway.

Analysis of oxidative stress markers. Alteration of the mitochondrial membrane potential $\left(\Delta \Psi_{\mathrm{m}}\right)$ in the apoptotic cells was determined by JC-1 fluorescence, and the results revealed a dose-dependent decrease in the membrane potential (Fig. 4A). SW620 cells treated with QTL (Fig. 4B) also exhibited a significant $(\mathrm{P}<0.01)$ increase of intracellular ROS production in a dose-dependent manner $(48 \mathrm{~h})$ as compared to the control cells, indicating ROS-mediated apoptosis in these cells. The MDA level was markedly increased by QTL $(\mathrm{P}<0.01$ for all doses; Fig. 4C). After 
A

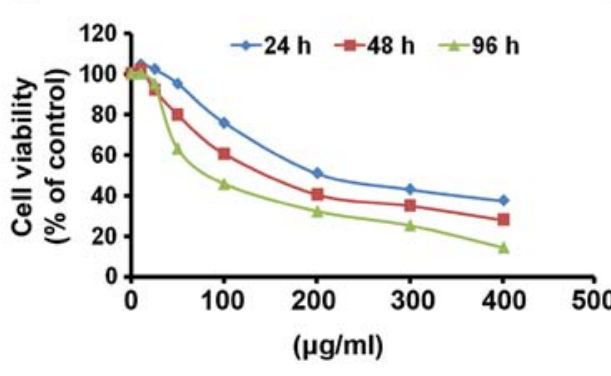

B Con

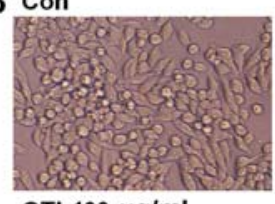

QTL100 $\mu \mathrm{g} / \mathrm{ml}$

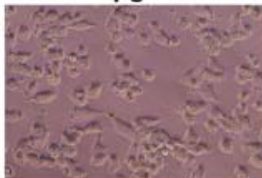

QTL $50 \mu \mathrm{g} / \mathrm{ml}$

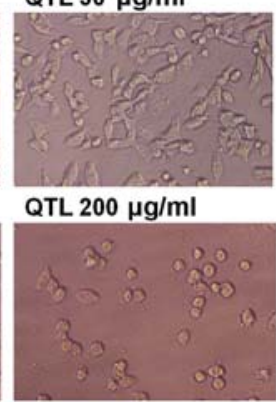

Figure 1. Effect of QTL on the growth of SW620 cells. (A) Cell viability. The cells were treated with different concentrations of QTL (12.5-400 $\mu$ g/ml), which affected cell viability in a time-dependent manner (24, 48 and $96 \mathrm{~h}$, respectively). Data are expressed as the means \pm SD ( $\mathrm{n}=6$ ). (B) Morphological changes. The cells were treated with 50, 100 and $200 \mu \mathrm{g} / \mathrm{ml}$ of QTL. After $48 \mathrm{~h}$, the images were captured by light microscopy (magnification, x200). QTL, quercetrin from T. sinensis leaves.

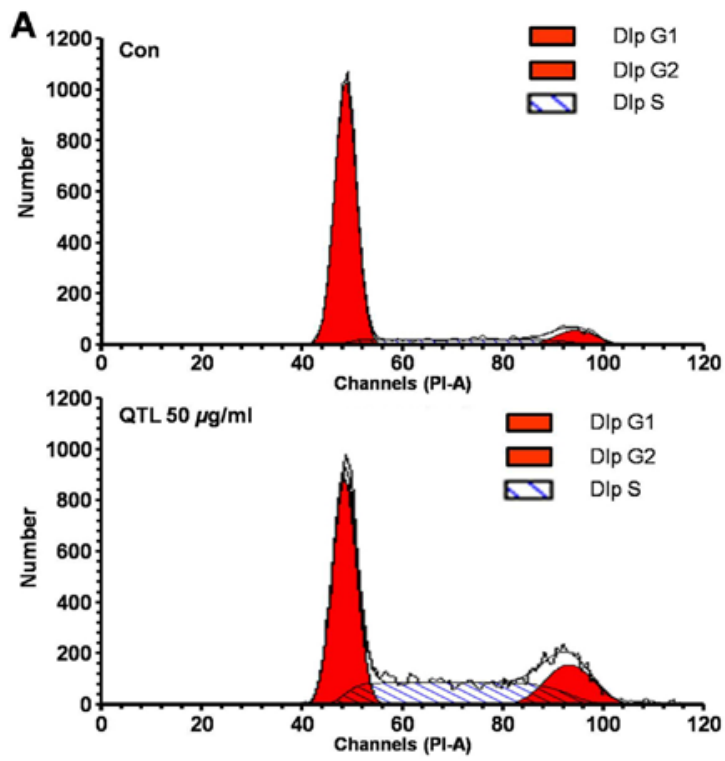

B
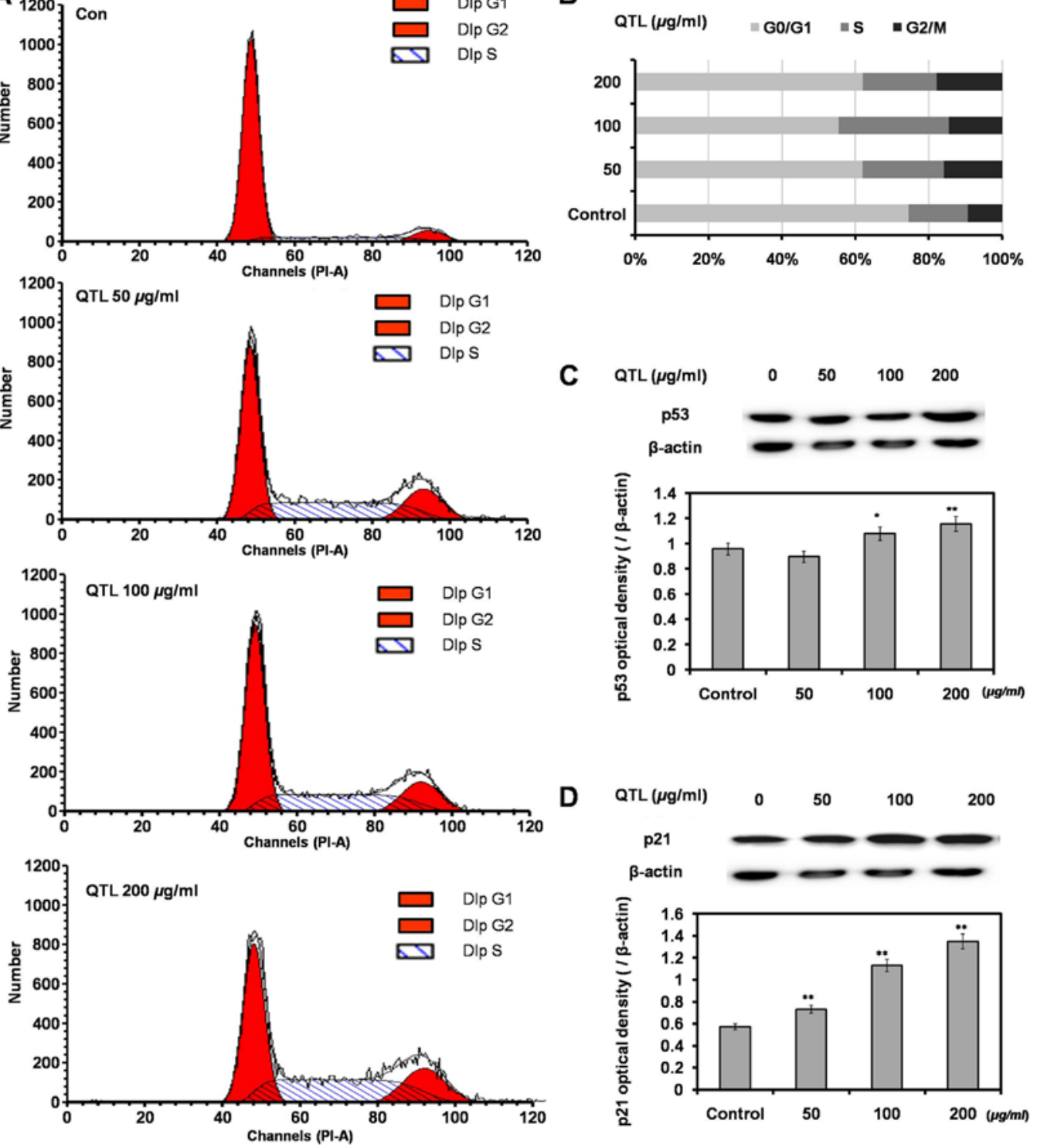

Figure 2. Cell cycle analysis. Cells exposed to QTL (50, 100 and $200 \mu \mathrm{g} / \mathrm{ml}$ ) for $48 \mathrm{~h}$, and collected for analysis using flow cytometry revealing (A) the cell cycle state, $(B)$ the cell cycle distribution and $(\mathrm{C}$ and $\mathrm{D})$ western blotting. Each bar represents the mean $\pm \mathrm{SD}$ referred to the corresponding $\beta$-actin values ( $\mathrm{n}=3$ ); ${ }^{*} \mathrm{P}<0.05$ and ${ }^{* *} \mathrm{P}<0.01$ compared to the control. QTL, quercetrin from $T$. sinensis leaves.

incubation with 50, 100 and $200 \mu \mathrm{g} / \mathrm{ml}$ of QTL for $48 \mathrm{~h}$ respectively, the expression of CAT and GPX mRNAs was markedly decreased $(\mathrm{P}<0.01)$, while the changes in the expression of SOD mRNA were non-significantly $(\mathrm{P}>0.05)$ 

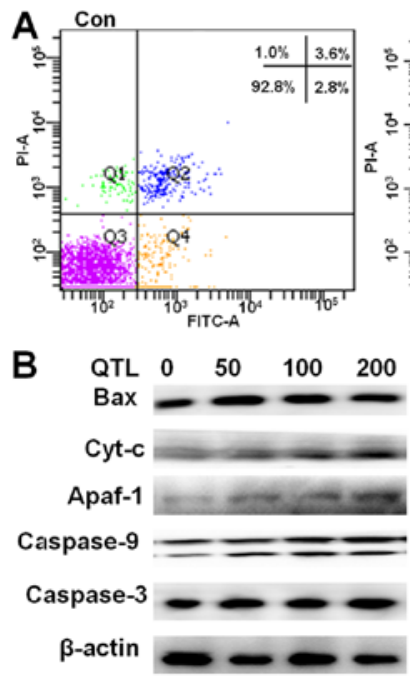

E

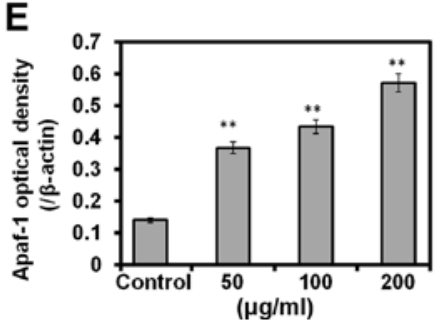

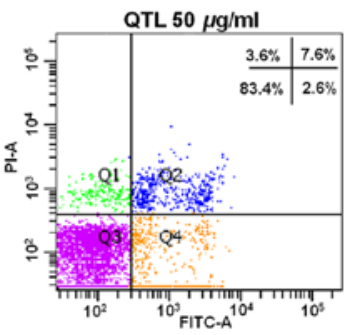

C
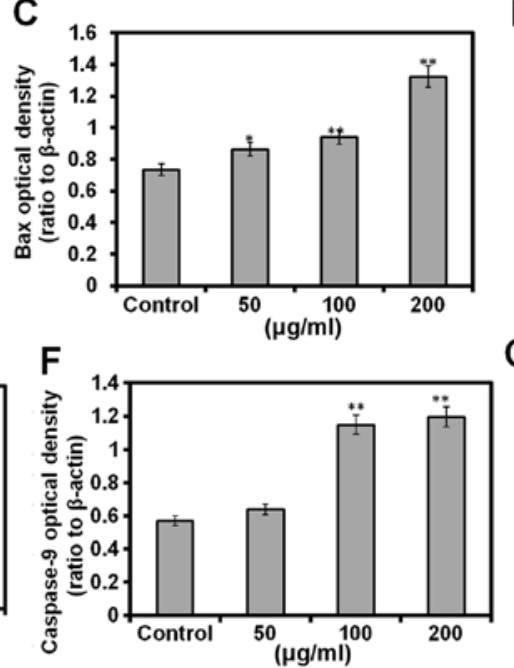
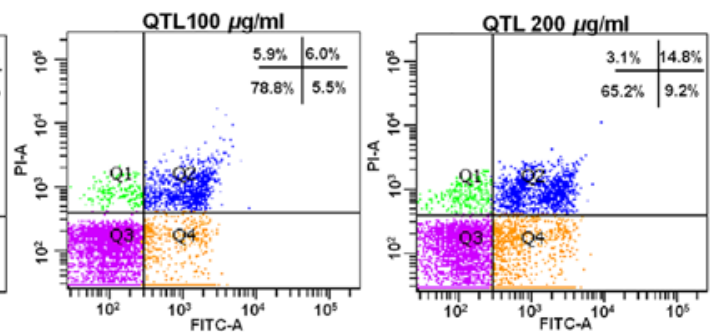

D

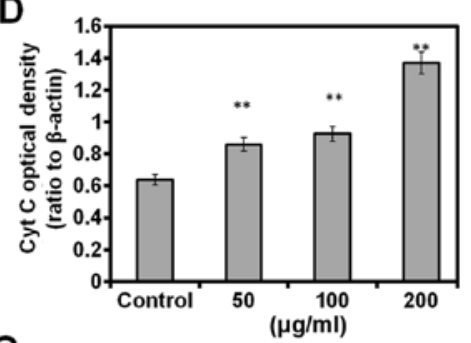

G

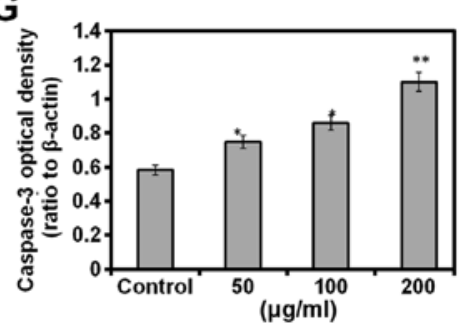

Figure 3. Effect of QTL on apoptosis and apoptosis-related proteins. SW620 cells were exposed to QTL (50, 100 and $200 \mu \mathrm{g} / \mathrm{ml}$ for $48 \mathrm{~h}$, and collected for analysis of apoptosis using (A) flow cytometry and (B-G) western blotting. Each bar represents the mean \pm SD referred to the corresponding $\beta$-actin values $(\mathrm{n}=3) ;{ }^{*} \mathrm{P}<0.05$ and ${ }^{* *} \mathrm{P}<0.01$ compared to the control. QTL, quercetrin from $T$. sinensis leaves.
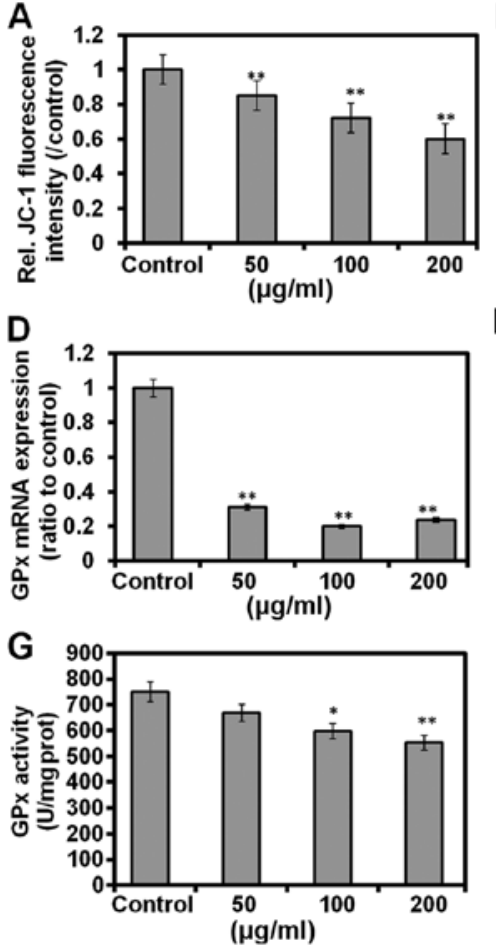

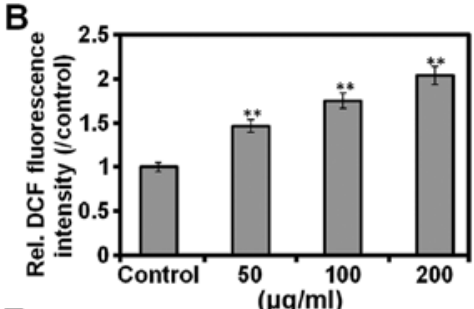

E
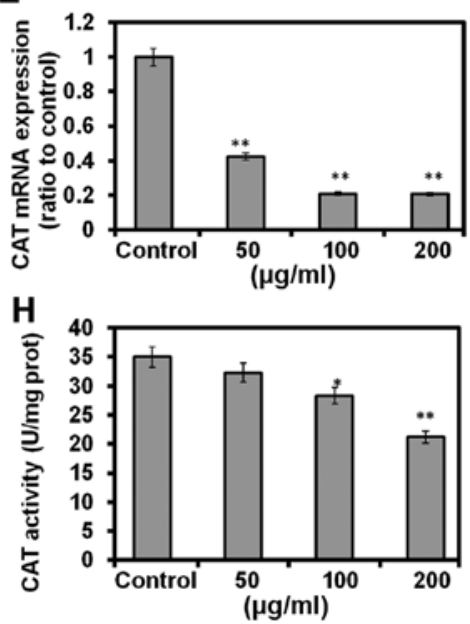

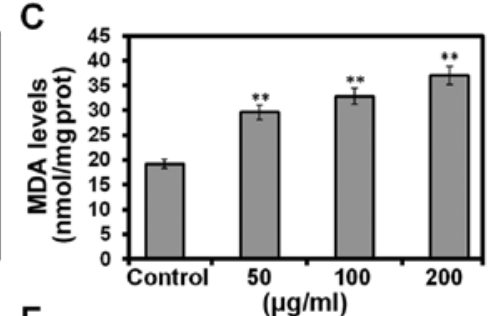

$F$

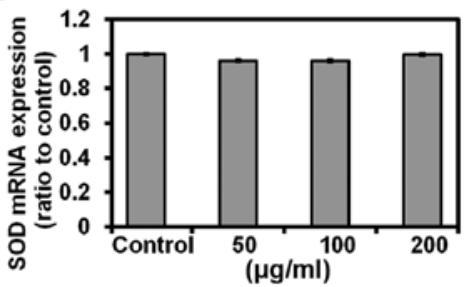

1

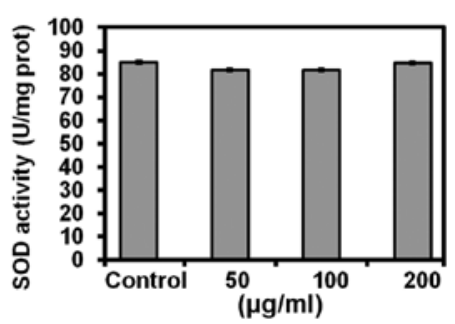

Figure 4. Effect of QTL on oxidative stress. (A) Mitochondrial membrane potential $\left(\Delta \Psi_{\mathrm{m}}\right)$, (B) ROS, (C) MDA levels and (D-I) the gene expression and activity of antioxidant enzymes were determined. Data are expressed as the means $\pm \mathrm{SD}(\mathrm{n}=6)$; ${ }^{*} \mathrm{P}<0.05$ and ${ }^{* * *} \mathrm{P}<0.01$ compared to the control. QTL, quercetrin from T. sinensis leaves.

changed (Fig. 4D-F). Similarly, treatment with $25-100 \mu \mathrm{g} / \mathrm{ml}$ of QTL elicited no changes in the activity of SOD in SW620 cells (Fig. 4I). Notably, a significant decrease of GPx ( $\mathrm{P}<0.01$; Fig. $4 \mathrm{G})$ and CAT $(\mathrm{P}<0.01$; Fig. $4 \mathrm{H})$ activities was observed 

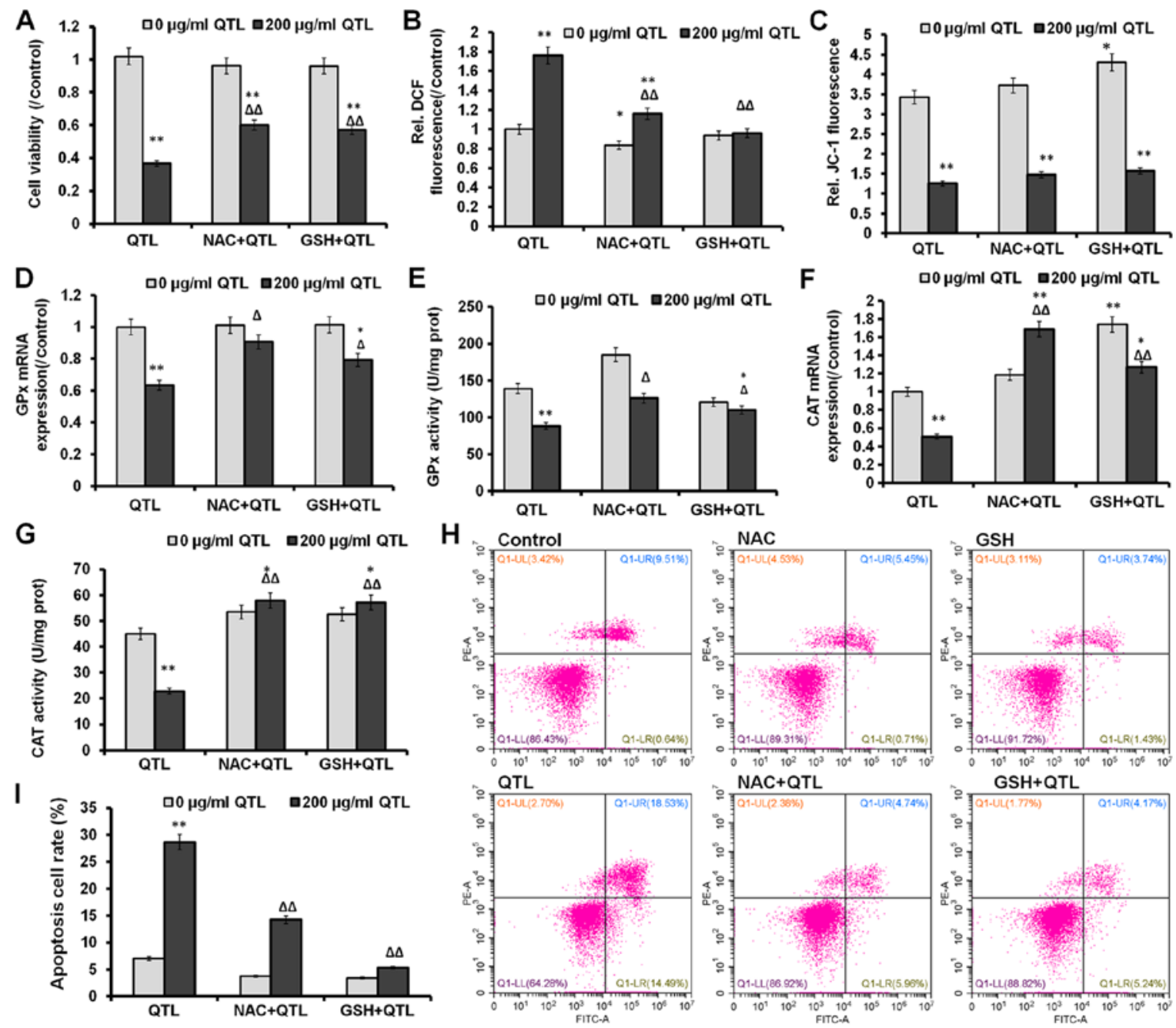

Figure 5. Effect of NAC or GSH on QTL-treated SW620 cells. Cells were treated with $200 \mu \mathrm{g} / \mathrm{ml}$ QTL for $24 \mathrm{~h}$ following $4 \mathrm{~h}$ preincubation with $5 \mathrm{mM}$ NAC or $1 \mathrm{mM} \mathrm{GSH}$. (A) Cell viability, (B) ROS production, (C) $\Delta \Psi_{\mathrm{m}}$, mRNA expression of (D) GPx and (F) CAT, the enzyme activity of (E) GPx and (G) CAT, and (H and I) apoptosis status were determined. Data are expressed as the mean $\pm \mathrm{SD}(\mathrm{n}=6) ;{ }^{*} \mathrm{P}<0.05$ and ${ }^{* *} \mathrm{P}<0.01$ compared to the control, ${ }^{\Delta} \mathrm{P}<0.05$ and ${ }^{\Delta \Delta} \mathrm{P}<0.01$ compared to the QTL-treated group. QTL, quercetrin from T. sinensis leaves.

after the treatment of SW620 cells with 50 and $100 \mu \mathrm{g} / \mathrm{ml}$ of QTL for $48 \mathrm{~h}$, respectively.

Effects of QTL in combination with NAC or GSH on cell viability and oxidative stress markers in SW620 cells. SW620 cells were pretreated with $5 \mathrm{mM}$ NAC (a ROS scavenger) and $1 \mathrm{mM}$ GSH (an antioxidant) and then exposed to $200 \mu \mathrm{g} / \mathrm{ml}$ of QTL for $24 \mathrm{~h}$. The previously observed decrease of cell viability in SW620 cells elicited by QTL was markedly $(\mathrm{P}<0.01)$ reversed by NAC or GSH compared to cells treated with QTL only, whereby NAC treatment only insignificantly $(\mathrm{P}>0.05)$ affected cell viability (Fig. 5A). Pretreatment with both NAC and GSH also partially abrogated the QTL-mediated increase of ROS levels $(\mathrm{P}<0.01)$, while it had only an insignificantly (P>0.05) effect on the QTL-mediated loss of $\Delta \Psi_{\mathrm{m}}$ (Fig. 5C). In addition, treatment with QTL partially $(\mathrm{P}<0.05$ in both cases) reversed the changes of GPx mRNA expression level and its activity (Fig. 5D and E). The pretreatment with both NAC and GSH also significantly $(\mathrm{P}<0.01$ in both cases) increased the mRNA expression level and enzyme activity of CAT after pretreatment with both NAC and GSH (Fig. 5F and G). As shown in Fig. 5H and I, QTL significantly increased apoptosis
$(\mathrm{P}<0.01)$ in SW620 cells, whereas QTL pretreatment with both NAC and GSH markedly decreased $(\mathrm{P}<0.01$ in both cases) the apoptosis rate. Overall, these data demonstrated that QTL-induced apoptosis in SW620 cells was mediated by the oxidative stress pathway.

\section{Discussion}

Our data demonstrated that quercetrin from Toona sinensis leaves (QTL) significantly decreased the viability of the SW620 human colorectal cancer cell line, caused cell cycle arrest in the G2/M phase and induced apoptosis. Cell cycle arrest and apoptosis are common phenomena after DNA-damaging treatment. It was reported that aqueous extracts from the leaves of $T$. sinensis arrested SKOV3 ovarian cancer cells at the G2/M phase and induced the apoptotic pathway (16). Cell cycle arrest or apoptosis in response to DNA damage was mediated primarily by transcription factor p53 (23). Moreover, p21 is a very important checkpoint gene in the cell cycle, and it is also regulated by the transcription of $\mathrm{p} 53$. Our findings are consistent with previous studies demonstrating that QTL increased the expression level of p53 and p21 proteins (24). 
Those results revealed that the QTL-induced inhibition of SW620 cell growth was partially due to the induction of G2/M arrest. Apoptosis is an ordered and orchestrated cellular event by which cells undergo inducible non-necrotic cellular suicide and thus it plays a crucial role in preventing carcinogenesis (25). Various phytochemicals induce apoptosis and change the morphology of cancer cells due to their pro-apoptotic activity, and consequently they are used for cancer prevention and cancer chemotherapy (26). In the present study, QTL was able to induce apoptosis in the SW620 cells in a dose-dependent manner, as was demonstrated by flow cytometric analysis. The tumor-suppressor p 53 has been revealed to differentially regulate Bcl-2 and Bax levels both in vitro and in vivo (27). Using western blotting, increases in the protein levels of the apoptosis markers Bax, cytochrome $c$ caspase-9, Apaf-1 and caspase-3 were detected indicating that QTL-induced apoptosis of SW620 was tightly associated with the mitochondrial apoptotic pathway.

Mitochondria are key organelles crucial for cell survival, and are conversely a source of ROS during apoptosis. The loss of $\Delta \Psi_{\mathrm{m}}$ is often, but not always observed to be associated with the early stages of apoptosis (28). The collapse of this potential is believed to coincide with the opening of the mitochondrial permeability transition pores, leading to the release of cytochrome $c$ into the cytosol. In the cytoplasm, cytochrome $c$ combines with caspase-9, Apaf-1 and dATP to form the apoptosome complex which in turn activates caspase- $9,-3$ and -7 . ROS have been implicated as a second messengers in multiple signaling pathways and can play a significant role in the process of apoptosis by regulating the activity of certain enzymes involved in the cell death pathway (29). In cancer cells, ROS initiates cell transformation by causing alterations during DNA replication (30). Moreover, enhancement of ROS production has long been associated with the apoptotic response induced by anticancer agents (31-33). Several natural compounds, such as phenolic phytochemicals used for cancer treatment have been shown to decrease the $\Delta \Psi_{\mathrm{m}}$ leading to the increased generation of intracellular ROS and apoptosis (31). Similar results were observed in the present study when SW620 colorectal cancer cells were treated with QTL. Our findings along with other studies, therefore revealed that QTL acts as an antiproliferative agent via the overproduction of ROS and the loss of $\Delta \Psi_{\mathrm{m}}$.

Furthermore, previous in vitro anticancer studies of anticancer agents revealed that the increased ROS levels in primary cancer cells were associated with a decrease of antioxidants, such as SOD, GPx and catalase (CAT) (34). It is also known that many types of human cancer cells can exist in a highly oxidative state due to the decreased levels of protective antioxidant enzymes as compared to their normal tissue counterparts (35). Natural phytochemicals are known to deplete intracellular GSH and increase intracellular ROS to a level that can cause cell death $(36,37)$. In the present study, treatment with QTL significantly decreased the mRNA expression and activity of CAT and GPx in the SW620 cells.

Previous studies demonstrated that leaf extracts of Toona sinensis are cytotoxic to DU145 prostate cancer cells, due to the generation of reactive oxygen species (ROS) and mitochondria-mediated apoptosis, which was reversed by the antioxidants CAT and $N$-acetyl cysteine (NAC) (22).
The present study also investigated the effects of NAC (a well-known antioxidant and a precursor of GSH biosynthesis) or GSH on QTL-treated SW620 cells. Treatment with only NAC did not significantly affect cell viability, $\Delta \Psi_{\mathrm{m}}$ and mRNA expression of CAT and GSH in SW620 cells. However, NAC significantly mitigated QTL-induced cytotoxicity and ROS production, which was accompanied by the decrease of CAT and GPx mRNA expression in these cells. Treatment with only GSH slightly decreased the reduction of cell viability, and did not enhance ROS levels in SW620 cells. However, it should be noted that GSH significantly mitigated the reduction of cell viability, the increase of ROS levels and the decrease of CAT and GPx activity, as well as the apoptosis rate in QTL-treated SW620 cells. Therefore, our results support the notion that QTL-induced apoptotic cell death in the SW620 cancer cell line was mediated by the excessive generation of ROS.

In conclusion, we present evidence for the first time that QTL has a potential role in suppressing human colorectal cancer via inhibition of tumor cell proliferation, induction of cell cycle arrest and apoptosis and enhancement of oxidative stress, providing a therapeutic strategy for human colorectal cancer treatment.

\section{Acknowledgements}

The present study was financed by the Special Fund for Forest Scientific Research in the Public Welfare (201304811), by the National Natural Science Foundation of China (31101266), and by the Scientific and Technical Foundation of Shaanxi Province (2014JM41005).

\section{References}

1. Torre LA, Bray F, Siegel RL, Ferlay J, Lortet-Tieulent J and Jemal A: Global cancer statistics, 2012. CA Cancer J Clin 65: 87-108, 2015.

2. Redondo-Blanco S, Fernández J, Gutiérrez-Del-Río I, Villar CJ and Lombó F: New insights toward colorectal cancer chemotherapy using natural bioactive compounds. Front Pharmacol 8: $109,2017$.

3. Aghajanpour M, Nazer MR, Obeidavi Z, Akbari M, Ezati P and Kor NM: Functional foods and their role in cancer prevention and health promotion: A comprehensive review. Am J Cancer Res 7: 740-769, 2017.

4. Yang H, Gu Q, Gao T, Wang X, Chue P, Wu Q and Jia X: Flavonols and derivatives of gallic acid from young leaves of Toona sinensis (A. Juss.) Roemer and evaluation of their anti-oxidant capacity by chemical methods. Pharmacogn Mag 10: 185-190, 2014.

5. Yu WJ, Chang CC, Kuo TF, Tsai TC and Chang SJ: Toona sinensis Roem leaf extracts improve antioxidant activity in the liver of rats under oxidative stress. Food Chem Toxicol 50: 1860-1865, 2012.

6. Yang HL, Chen SC, Lin KY, Wang MT, Chen YC, Huang HC, Cho HJ, Wang L, Kumar KJ and Hseu YC: Antioxidant activities of aqueous leaf extracts of Toona sinensis on free radical-induced endothelial cell damage. J Ethnopharmacol 137: 669-680, 2011.

7. Wu JG, Peng W, Yi J, Wu YB, Chen TQ, Wong KH and Wu JZ: Chemical composition, antimicrobial activity against Staphylococcus aureus and a pro-apoptotic effect in SGC-7901 of the essential oil from Toona sinensis (A. Juss.) Roem. leaves. J Ethnopharmacol 154: 198-205, 2014.

8. Huang PJ, Hseu YC, Lee MS, Senthil Kumar KJ, Wu CR, Hsu LS, Liao JW, Cheng IS, Kuo YT, Huang SY, et al: In vitro and in vivo activity of gallic acid and Toona sinensis leaf extracts against HL-60 human premyelocytic leukemia. Food Chem Toxicol 50: 3489-3497, 2012

9. Yang CJ, Huang YJ, Wang CY, Wang CS, Wang PH, Hung JY, Wang TH, Hsu HK, Huang HW, Kumar SP, et al: Antiproliferative and antitumorigenic activity of Toona sinensis leaf extracts in lung adenocarcinoma. J Med Food 13: 54-61, 2010. 
10. Su YF, Yang YC, Hsu HK, Hwang SL, Lee KS, Lieu AS, Chan TF and Lin CL: Toona sinensis leaf extract has antinociceptive effect comparable with non-steroidal anti-inflammatory agents in mouse writhing test. BMC Complement Altern Med 15: 70, 2015.

11. Yang HL, Huang PJ, Liu YR, Kumar KJ, Hsu LS, Lu TL, Chia YC, Takajo T, Kazunori A and Hseu YC: Toona sinensis inhibits LPS-induced inflammation and migration in vascular smooth muscle cells via suppression of reactive oxygen species and NF- $\kappa$ B signaling pathway. Oxid Med Cell Longev 2014: 901315, 2014.

12. Hsiang CY, Hseu YC, Chang YC, Kumar KJ, Ho TY and Yang HL: Toona sinensis and its major bioactive compound gallic acid inhibit LPS-induced inflammation in nuclear factor $-\kappa \mathrm{B}$ transgenic mice as evaluated by in vivo bioluminescence imaging. Food Chem 136: 426-434, 2013.

13. Liu HW, Huang WC, Yu WJ and Chang SJ: Toona sinensis ameliorates insulin resistance via AMPK and PPAR $\gamma$ pathways. Food Funct 6: 1855-1864, 2015.

14. Hsieh TJ, Tsai YH, Liao MC, Du YC, Lien PJ, Sun CC, Chang FR and Wu YC: Anti-diabetic properties of non-polar Toona sinensis Roem extract prepared by supercritical- $\mathrm{CO}_{2}$ fluid. Food Chem Toxicol 50: 779-789, 2012.

15. Chang HC, Hung WC, Huang MS and Hsu HK: Extract from the leaves of Toona sinensis roemor exerts potent antiproliferative effect on human lung cancer cells. Am J Chin Med 30: 307-314, 2002.

16. Chang HL, Hsu HK, Su JH, Wang PH, Chung YF, Chia YC, Tsai LY, Wu YC and Yuan SS: The fractionated Toona sinensi leaf extract induces apoptosis of human ovarian cancer cells and inhibits tumor growth in a murine xenograft model. Gynecol Oncol 102: 309-314, 2006.

17. Kakumu A, Ninomiya M, Efdi M, Adfa M, Hayashi M, Tanaka K and Koketsu M: Phytochemical analysis and antileukemic activity of polyphenolic constituents of Toona sinensis. Bioorg Med Chem Lett 24: 4286-4290, 2014.

18. Yang HL, Chang WH, Chia YC, Huang CJ, Lu FJ, Hsu HK and Hseu YC: Toona sinensis extracts induces apoptosis via reactive oxygen species in human premyelocytic leukemia cells. Food Chem Toxicol 44: 1978-1988, 2006

19. Wang CY, Lin KH, Yang CJ, Tsai JR, Hung JY, Wang PH, Hsu HK and Huang MS: Toona sinensis extracts induced cell cycle arrest and apoptosis in the human lung large cell carcinoma. Kaohsiung J Med Sci 26: 68-75, 2010.

20. Zhen H, Zhang Y, Fang Z, Huang Z, You C and Shi P: Toona sinensis and Moschus decoction induced cell cycle arrest in human cervical carcinoma HeLa cells. Evid Based Complement Alternat Med 2014: 121276, 2014.

21. Liu J, You L, Wang C and Liu R: Antioxidization and antiproliferation of extract from leaves of Toona sinensis. Zhong Nan Da Xue Xue Bao Yi Xue Ban 37: 42-47, 2012.

22. Chen HM, Wu YC, Chia YC, Chang FR, Hsu HK, Hsieh YC, Chen CC and Yuan SS: Gallic acid, a major component of Toona sinensis leaf extracts, contains a ROS-mediated anti-cancer activity in human prostate cancer cells. Cancer Lett 286: 161-171, 2009.
23. Mirzayans R, Andrais B, Kumar P and Murray D: Significance of wild-type p53 signaling in suppressing apoptosis in response to chemical genotoxic agents: Impact on chemotherapy outcome. Int J Mol Sci 18: 18, 2017.

24. Fischer M, Quaas M, Steiner L and Engeland K: The p53-p21-DREAM-CDE/CHR pathway regulates G2/M cell cycle genes. Nucleic Acids Res 44: 164-174, 2016.

25. Mbaveng AT, Kuete V and Efferth T: Potential of Central, Eastern and Western Africa medicinal plants for cancer therapy: Spotlight on resistant cells and molecular targets. Front Pharmacol 8: 343, 2017.

26. Shukla S, Meeran SM and Katiyar SK: Epigenetic regulation by selected dietary phytochemicals in cancer chemoprevention. Cancer Lett 355: 9-17, 2014.

27. Abraha AM and Ketema EB: Apoptotic pathways as a therapeutic target for colorectal cancer treatment. World J Gastrointest Oncol 8: 583-591, 2016.

28. Suzuki Y, Hasegawa H, Tsuji T, Tsuruda K, Sasaki D, Ishihara K, Nagai K, Yanagihara K, Yamada Y and Kamihira S: Relationships of diverse apoptotic death process patterns to mitochondrial membrane potential $\left(\Delta \psi_{\mathrm{m}}\right)$ evaluated by three-parameter flow cytometric analysis. Cytotechnology 65: 59-70, 2013.

29. Marchi S, Giorgi C, Suski JM, Agnoletto C, Bononi A, Bonora M, De Marchi E, Missiroli S, Patergnani S, Poletti F, et al: Mitochondria-ros crosstalk in the control of cell death and aging. J Signal Transduct 2012: 329635, 2012.

30. Panieri E and Santoro MM: ROS homeostasis and metabolism: A dangerous liason in cancer cells. Cell Death Dis 7: e2253, 2016.

31. Bishayee K, Ghosh S, Mukherjee A, Sadhukhan R, Mondal J and Khuda-Bukhsh AR: Quercetin induces cytochrome- $c$ release and ROS accumulation to promote apoptosis and arrest the cell cycle in $\mathrm{G} 2 / \mathrm{M}$, in cervical carcinoma: Signal cascade and drug-DNA interaction. Cell Prolif 46: 153-163, 2013.

32. Zhou Y, Shu F, Liang X, Chang H, Shi L, Peng X, Zhu J and Mi M: Ampelopsin induces cell growth inhibition and apoptosis in breast cancer cells through ROS generation and endoplasmic reticulum stress pathway. PLoS One 9: e89021, 2014.

33. Kim J, Kim J and Bae JS: ROS homeostasis and metabolism: A critical liaison for cancer therapy. Exp Mol Med 48: e269, 2016.

34. Abdal Dayem A, Hossain MK, Lee SB, Kim K, Saha SK, Yang GM, Choi HY and Cho SG: The role of reactive oxygen species (ROS) in the biological activities of metallic nanoparticles. Int J Mol Sci 18: 18, 2017.

35. Banerjee $\mathrm{K}$ and Mandal M: Oxidative stress triggered by naturally occurring flavone apigenin results in senescence and chemotherapeutic effect in human colorectal cancer cells. Redox Biol 5: 153-162, 2015.

36. Ferraresi R, Troiano L, Roat E, Lugli E, Nemes E, Nasi M, Pinti M, Fernandez MI, Cooper EL and Cossarizza A: Essential requirement of reduced glutathione (GSH) for the anti-oxidant effect of the flavonoid quercetin. Free Radic Res 39: 1249-1258, 2005.

37. Ramos AM and Aller P: Quercetin decreases intracellular GSH content and potentiates the apoptotic action of the antileukemic drug arsenic trioxide in human leukemia cell lines. Biochem Pharmacol 75: 1912-1923, 2008. 